Significant hardness enhancement in an Al-Cu-Mg alloy with high $\mathrm{Cu}: \mathrm{Mg}$ ratio by microalloying with $\mathrm{Si}$ and $\mathrm{Ge}$.

M.Victoria Castro-Riglos, Nicolás Morello, Alfredo Tolley

PII:

S2589-1529(18)30154-6

DOI: https://doi.org/10.1016/j.mtla.2018.09.025

Reference: MTLA 118

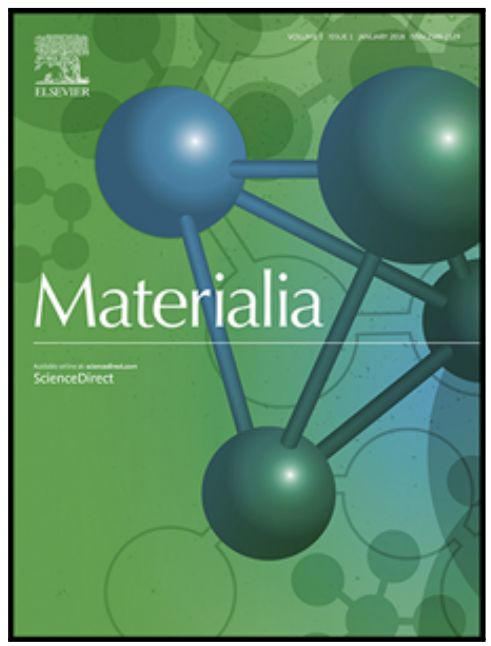

To appear in:

Materialia

Received date:

21 August 2018

Revised date:

22 September 2018

Accepted date:

22 September 2018

Please cite this article as: M.Victoria Castro-Riglos, Nicolás Morello, Alfredo Tolley, Significant hardness enhancement in an Al-Cu-Mg alloy with high Cu:Mg ratio by microalloying with $\mathrm{Si}$ and $\mathrm{Ge}$., Materialia (2018), doi: https://doi.org/10.1016/j.mtla.2018.09.025

This is a PDF file of an unedited manuscript that has been accepted for publication. As a service to our customers we are providing this early version of the manuscript. The manuscript will undergo copyediting, typesetting, and review of the resulting proof before it is published in its final form. Please note that during the production process errors may be discovered which could affect the content, and all legal disclaimers that apply to the journal pertain. 


\title{
Significant hardness enhancement in an Al-Cu-Mg alloy with high Cu:Mg ratio by microalloying with Si and Ge.
}

\author{
M.Victoria Castro-Riglos ${ }^{\mathrm{a}, \mathrm{b}, 1}$, Nicolás Morello ${ }^{\mathrm{a}}$, Alfredo Tolley ${ }^{\mathrm{a}, \mathrm{b}}$. \\ aDivisión Física de Metales, Centro Atómico Bariloche, Av.Bustillo 9500, S. C. de \\ Bariloche, (8400), Rio Negro, Argentina. \\ ${ }^{\text {b} C o n s e j o ~ N a c i o n a l ~ d e ~ I n v e s t i g a c i o n e s ~ C i e n t i ́ f i c a s ~ y ~ T e ́ c n i c a s ~(C O N I C E T), ~ A r g e n t i n a . ~}$
}

\begin{abstract}
The evolution of hardness in an Al-Cu-Mg based alloy with high Cu:Mg ratio (= 2, at. \%) microalloyed with Si and Ge was studied during artificial ageing treatment performed at $190^{\circ} \mathrm{C}$. The results were compared to those obtained in a similar alloy with no $\mathrm{Mg}$ content. The hardness evolution in the Mg containing alloy was similar to that of the Mg free alloy, but shifted by about 50 Hv to higher values for all ageing times. The peak hardness occurred after 3 hs ageing in both alloys, with a value slightly above 200 $\mathrm{Hv}$ in the Mg containing alloys. The microstructure of the peak aged and the overaged condition were characterized by means of transmission electron microscopy (TEM). For the Mg-containing alloy the microstructure of the peak aged condition consisted of plate-shaped precipitates, with a very similar structure to that of the $\theta^{\prime}$ phase and a high density of small needle-shaped precipitates lying along the $\langle 100\rangle_{\mathrm{Al}}$ directions. In the peak aged and overaged conditions the needle-shaped precipitates were found to belong to the $Q^{\prime}$ phase $\left(\mathrm{Al}_{4} \mathrm{Cu}_{2} \mathrm{Mg}_{8} \mathrm{Si}_{7}\right)$ or its precursor phases, previously observed in the Al-Mg-Si system with minor Cu additions.
\end{abstract}

\footnotetext{
${ }^{1}$ Corresponding Author: Current Adress: Helmholtz Zentrum Geesthacht (HZG), Max Planck Strasse 1, 21502, Geesthacht, Germany. E-mail: viquiriglos@gmail.com
} 
Keywords: Al-Cu-Mg alloys; TEM; hardness; microstructure; precipitation.

\section{Introduction}

Age hardenable aluminum alloys, like those from $\mathrm{Al}-\mathrm{Cu}$ and $\mathrm{Al}-\mathrm{Mg}$-Si systems, are of great industrial interest, because during the ageing heat treatments they can be hardened by the formation of precipitates from secondary phases that hinder dislocation displacement $[1,2]$. In Al-Cu the maximum hardness or "peak ageing" (PA) condition is achieved when a high precipitate density from the metastable $\theta^{\prime \prime}$ phase is formed. For longer ageing treatments (over-aged condition), the $\theta^{\prime}$ phase is formed exhibiting a low density of larger precipitates [3]. These hardening phases in the Al-Cu system present either $\operatorname{disc}\left(\theta^{\prime \prime}\right)$ or plate like $\left(\theta^{\prime}\right)$ morphologies oriented parallel to $\{001\}_{\mathrm{Al}}$ planes [3]. Minor additions of other elements in this alloy have proved to stimulate an earlier and more abundant precipitation of $\theta^{\prime}$ phase particles. Thus, a higher hardness peak is obtained at a reduced ageing time [4,5].

In the Al-Mg-Si system, several different metastable phases, for example U1, U2, $\beta^{\prime}$, $\beta^{\prime \prime}$, have been reported to form needle shaped precipitates oriented parallel to the Al matrix $<100>$ directions. Here the peak aged microstructure is dominated by $\beta^{\prime \prime}$ precipitates [6,7]. The addition of $\mathrm{Cu}$ into Al-Mg-Si alloys, with a low $\mathrm{Cu}$ :Mg ratio ( $\leq$ 0.3) widens the variety of needle-shaped precipitates that form in this system, through the development of other Cu-containing phases like $Q^{\prime}, Q_{\text {and }} Q^{\prime}$ precursors [8]. In this case, the hardening in the peak aged condition is not dominated by $\beta^{\prime \prime}$ but by Cucontaining needles. Moreover, the replacement of Si with Ge and minor additions of $\mathrm{Cu}$ to $\mathrm{Al}-\mathrm{Mg}$-Si-Ge (with low $\mathrm{Cu}: \mathrm{Mg}$ ratio) were studied, leading once again to the observation of needle-shaped precipitates parallel to $<001>_{A I}[9,10]$. 
The Cu:Mg ratio is known to determine which phases form during ageing within the AlCu-Mg system [11]. However, the effects of microalloying additions on the precipitation processes and their influence on hardness for high $\mathrm{Cu}: \mathrm{Mg}$ ratio have not been fully explored. Attempts in this direction were performed by Ringer et al. [12-14] who studied Al-Cu-Mg based alloys (Cu:Mg > 5.5, at.\%) with $\mathrm{Ge}$ or $\mathrm{Si}+\mathrm{Ge}$ additions. Trace additions of Ge were found to produce a significant refinement of the $\theta^{\prime}$ precipitate dispersion and a higher aspect ratio of the $\theta^{\prime}$ plates, together with a fine scale dispersion of lath-shaped precipitates parallel to the $<001>$ lattice directions. In the case of adding together Si and Ge, the early stages of precipitation showed the formation of $\mathrm{Mg}-\mathrm{Ge}$ complexes, indicating a strong interaction between $\mathrm{Mg}$ and $\mathrm{Ge}$ was identified. At PA, $\theta^{\prime}$ precipitates were observed together with rod-shaped $\mathrm{Cu}$ $\mathrm{Mg}(\mathrm{Si})$ and $\mathrm{Mg}(\mathrm{Ge}, \mathrm{Si})$ zones. A more recent study in an $\mathrm{Al}-\mathrm{Cu}-\mathrm{Mg}(\mathrm{Cu}: \mathrm{Mg}=2$, at.\%) alloy with additions of $\mathrm{Si}$ and $\mathrm{Ge}$ in 1:1 proportion has shown that, for the PA condition, a high hardness value was achieved and the microstructure was composed of small needle shaped precipitates from an unknown phase together with plate-shaped precipitates, both in a high density [15]. In the present work, new studies concerning this alloy were carried out in order to further characterize the microstructure. For this purpose, an Al-2Cu-1Mg-0.5Si-0.5Ge (at.\%) was studied and compared to a similar alloy having no $\mathrm{Mg}$ content (Al-2Cu-0.5Si-0.5Ge, at.\%) which is already well characterized $[4,13]$. The hardness evolution was investigated in both alloys and the microstructural characterization in the PA and overaged conditions, was carried out by means of transmission electron microscopy (TEM).

\section{Experimental Procedure}


Two alloys were prepared by arc melting, having the following nominal composition (in at.\%):

-Alloy I: Al-2Cu-1Mg-0.5Si-0.5Ge (Cu:Mg=2)

-Alloy II: Al-2Cu-0.5Si-0.5Ge (no Mg content)

Both alloys were homogenized during $48 \mathrm{~h}$ at $520^{\circ} \mathrm{C}$ in sealed vycor tubes under $\mathrm{Ar}$ atmosphere and then quenched in water. Disc shaped samples with a diameter of about $10 \mathrm{~mm}$ and $1 \mathrm{~mm}$ thickness, were cut from the alloys. After that, a solution treatment was carried out at $520^{\circ} \mathrm{C}$ (in air atmosphere) during 15 minutes followed by water quenching to obtain a uniform initial state previous to artificial ageing treatments, that were carried out at $190 \circ \mathrm{C}$, for different ageing times $\left(\mathrm{t}_{\mathrm{a}}\right)$. Vickers microhardness was then measured with a Mitutoyo Hardness Testing Machine with a load of $100 \mathrm{~g}$ as a function of $t_{\mathrm{a}}$. For selected samples in peak aged condition, TEM specimens were produced by cutting smaller $3 \mathrm{~mm}$ diameter discs that were then sanded down to a thickness of $150 \mu \mathrm{m}$. The final thinning was carried out with double jet electro-polishing using a methanol-based electrolyte with a small content of sulphuric acid and hydrofluoric acid at $-30^{\circ} \mathrm{C}$ and an applied voltage of around $20 \mathrm{~V}$. TEM characterization was carried out using Philips CM 200 UT and FEI Tecnai F20 G2 microscopes, operating at $200 \mathrm{kV}$. The former was used for energy dispersive X-ray spectroscopy (EDXS) with a spatial resolution slightly below $10 \mathrm{~nm}$. Electron energy loss spectra were obtained with a Gatan Image Filter in a FEI-Titan (operated at 300 $\mathrm{kV}$ ) to measure the local foil thickness in order to determine precipitate densities. The thickness was computed by means of Digital Micrograph software. The value for the 
mean free path $(\lambda=143 \mathrm{~nm})$ for aluminum at $300 \mathrm{kV}$ was calculated using the following expression [17]:

$\lambda \approx\left[106 F\left(E_{0} / E_{m}\right)\right] /\left[\ln \left(2 \beta E_{0} / E_{m}\right)\right]$

where $F$ is a relativistic factor, $\beta$ is the collection semi-angle (in mrad), $E_{0}$ is the incident electron energy ( $300 \mathrm{keV}$ ) and $E_{m}$ is the mean energy loss, which depends on the chemical composition of the specimen, in eV (16.8 eV for Al polycrystals) [17]. For phase identification, diffraction patterns (DP) were simulated using Jems 4 software [18] and compared to the Fast Fourier Transform (FFT) obtained from High Resolution (HRTEM) images. The FFTs were calculated using Gatan's Microscopy Suite software [19], the same used for image acquisition.

\section{Results}

In Figure 1 the Vickers hardness evolution curves as a function of ageing time $\left(t_{a}\right)$ are displayed for the two alloys under study. It can be observed that in the Mg containing alloy the hardness curve presents significantly higher values for all ageing times compared to those obtained in Al-Cu-Si-Ge. The peak aged condition was reached at $t_{a}=3 \mathrm{~h}$ in both alloys. Even after prolonged overaging, the hardness of Alloy I was higher than the peak hardness of Alloy II. 


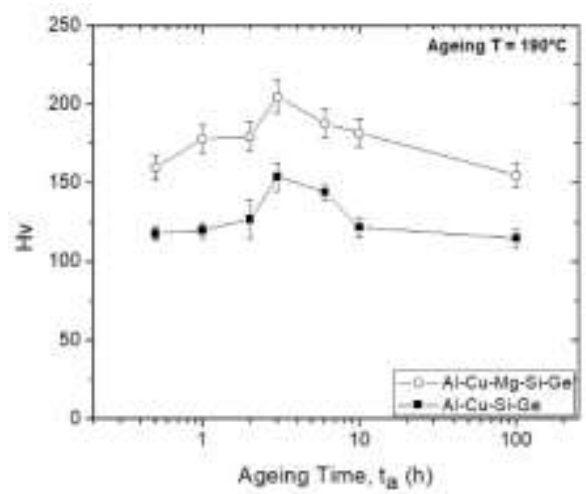

Figure 1: Hardness evolution as a function of ageing time (ta), for Alloy I (white circles) and Alloyll (black squares). All heat treatments were performed at $190^{\circ} \mathrm{C}$.

The microstructure corresponding to the peak aged condition of both alloys is illustrated in Figure 2. Both alloys show a high density of plate-shaped precipitates parallel to the $\{100\}$ matrix planes, together with other precipitates with different morphologies. Fig. $2 \mathrm{i}$ and $2 \mathrm{j}$ show selected area diffraction patterns along the [001] matrix zone axis (ZA). The matrix reflections are indexed. Additional reflections due to the precipitates are clearly observed. In Alloy II, Fig. 2j, these correspond to the $\theta^{\prime}$ phase [4]. In Fig. $2 i$ the additional reflections are similar, but streaking is much more pronounced. Figures 2c,d and 2g, h show two pairs of "Dark Field" /"Bright Field" (DF/BF) images obtained close to the $[001]_{A l}$ zone axis. The DF images $(2 \mathrm{c}, \mathrm{g})$ were obtained using the reflections indicated in Fig. $2 \mathrm{i}$ and $2 \mathrm{j}$, respectively. In Fig. $2 \mathrm{~g}$ and $2 \mathrm{~h}$, that correspond to Alloy II, the specimen was slightly tilted in order to strongly excite the $(200)_{A}$ r reflection. In this orientation, two variants of "edge-on" plate shaped $\theta^{\prime}$ precipitates and rod-shaped Si-Ge particles, the latter exhibiting a characteristic Moiré fringes [4], are observed in BF condition (Fig.2h) but in DF condition only one variant of “edge-on" $\theta$ ' precipitates together with “end-on" Si-Ge rods are highlighted (Fig. 2g).

Figures $2 c, d$ (Alloy I) show two variants of large edge-on plate-shaped precipitates and a high density of very small "dots". In addition, the BF image in Fig $2 \mathrm{~d}$ shows 
"segments" parallel to the "edge-on" plates but with weaker contrast. Such

precipitates are not highlighted in the dark field image of Fig. 2c, indicating that they

are of a different kind. No contrast due to Si-Ge rod-shaped precipitates was observed

either. The similarity of the additional reflections in the diffraction patterns of Fig $2 \mathrm{i}$

and $2 \mathrm{j}$, and the morphology of the plate-shaped precipitates in both alloys suggest that

in Alloy I the plate-shaped precipitates correspond to the $\theta^{\prime}$ phase, or a phase with a

very similar structure. In addition, the possibility that these plates could belong to the

C phase from ref. [8] was discarded because the diffraction patterns observed in C phase are clearly different from those observed in Alloy l's plates.

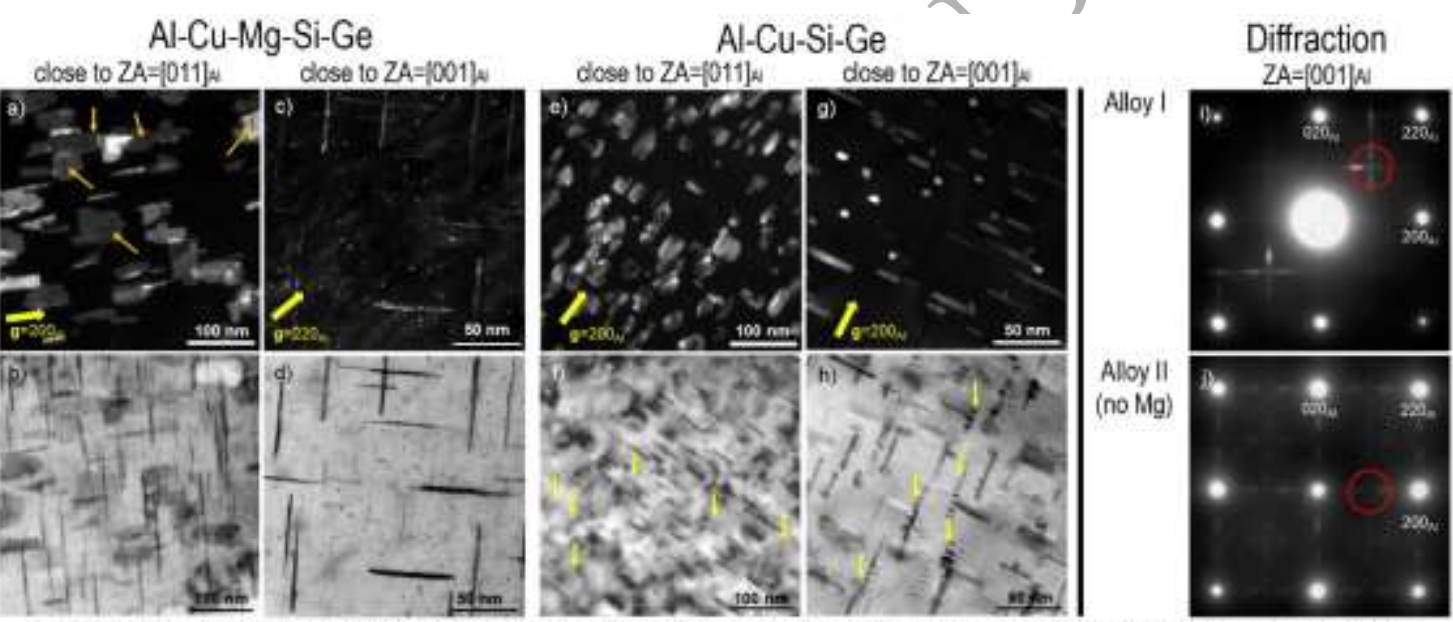

Figure 2: DF/BF images and diffraction palterns in $\mathrm{Al}-\mathrm{Cu}-\mathrm{Mg}-\mathrm{Si}-\mathrm{Ge}(\mathrm{a}-\mathrm{d}, \mathrm{i})$ and $\mathrm{Al}-\mathrm{Cu}-\mathrm{Si}-\mathrm{Ge}(\mathrm{e}-\mathrm{h}, \mathrm{j})$, ta=3 h (PA). In micrographs a , b. e, f the specimen is oriented close to $Z A=[011] \mathrm{N}$ condition and in $\mathrm{c}, \mathrm{d}, \mathrm{g}, \mathrm{h}$ the crientation is close to ZA=[001] $\mathrm{A}$ condition. Images a, b and $\mathrm{e}$ - $\mathrm{h}$ were acquired in two-beam condition with the $\mathrm{g}=(200) \mathrm{N}$ rellection while images $\mathrm{c}, \mathrm{d}$ were oblained in two-beam condition with the $\mathrm{g}=(220) \mathrm{N}$, indicaled by a thick arrow in the left bottom corner within each DF image. a, e) Incined plate-shaped precipitates, highlighted using the (112)e' refection. c, g) Edge-on plate-shaped precipitates, highlighted using weak reflections at $(1 / 2) \mathrm{g}$. BF images $\mathrm{f}$ and $\mathrm{h}$ obtained in two beam condition with $\mathrm{g}=$ (200) N. Rod-shaped Si-Ge precipitates parallel to [100/N, show Moire fringes (examples indicated with smal arrows). The Si-Ge rods are not observed in image b. BF in d displays "short segments" and "dots" from needle shaped precipitates oriented along <100>AL. i, j) DPs obtained in [001]W Zone Axis condition. For Alloy I the weak refiections display a marked streaking.

Figures $2 a, b$ (Alloy I) and 2e,f (Alloy II) show two additional sets of DF/BF images, acquired close to the $[011]_{\mathrm{Al}}$ zone axis orientation, in two beam condition with the $(200)_{\mathrm{Al}}$ reflection. The matrix was rotated from the exact [011] zone axis by about 10 o keeping the $(200)_{A I}$ in 2 beam condition in order to maximize the intensity of the $112_{\theta^{\prime}}$ reflection. The DF images in Fig 2a and 2e, show one variant of inclined plate-shaped precipitates using the $112_{\theta^{\prime}}$ reflection. The similarity of these images is a further 
indication that the plate-shaped precipitates in Alloy I have a structure very similar to the $\theta^{\prime}$ phase. It can be noticed that in the Mg containing alloy the aspect ratio of the plate shaped precipitates is higher, as previously reported in ref. [14]. Fig. $2 b$ and $2 f$ are the corresponding BF images, where a second variant of plate-shaped precipitates can be observed "edge-on", that is, with their habit plane perpendicular to the $g=$ $(200)_{A I}$ reflection.

Comparing the image in Fig. $2 c\left(Z A=[001]_{\mathrm{Al}}\right)$ with that in Fig. $2 \mathrm{a}\left(\mathrm{ZA}=[011]_{\mathrm{Al}}\right)$ it is noticed that the precipitates observed as "dots" in 2c became "segments" when tilting the specimen to obtain $\mathrm{ZA}=[011]_{\mathrm{Al}}$ the condition in $2 \mathrm{a}$ (some of these "segments" are pointed out by small arrows in Fig. 2a). This means that these precipitates are needle shaped with their long dimension parallel to $\langle 100\rangle_{\text {Al }}$ directions. Additionally, these needle-like precipitates in Fig. 2a frequently appear associated with the inclined $\theta^{\prime}$ precipitates, indicating that they serve as heterogeneous nucleation sites for the plateshaped precipitates. The needle morphology is similar to many phases observed in AlMg-Si and in Al-Mg-Si-Cu alloys with low Cu:Mg ratio [8-10].

\begin{tabular}{|c|c|c|c|c|}
\hline Alloy I & & \multicolumn{3}{|c|}{ Alloy II (No Mg) } \\
\hline Plates $\left(\theta^{\prime}\right.$-like $) \quad \rho_{\theta^{\prime}}\left(10^{-6} / \mathrm{nm}^{3}\right)$ & $3.5 \pm 0.4$ & Plates $\left(\theta^{\prime}\right)$ & $\rho_{\theta^{\prime}}\left(10^{-6} / \mathrm{nm}^{3}\right)$ & $4.5 \pm 0.5$ \\
\hline$l_{\theta^{\prime}}(n m)$ & $46 \pm 1$ & & $l_{\theta^{\prime}}(\mathrm{nm})$ & $28 \pm 0.8$ \\
\hline Needles $\quad \rho_{\mathrm{N}}\left(10^{-6} / \mathrm{nm}^{3}\right)$ & $16 \pm 2$ & Bars (Si-Ge) & $\rho_{\text {Si-Ge }}\left(10^{-6} / \mathrm{nm}^{3}\right)$ & $6.6 \pm 0.6$ \\
\hline$I_{N}(\mathrm{~nm})$ & $\leq 15$ & & $l_{\text {Si-Ge }}(n m)$ & $18 \pm 0.4$ \\
\hline
\end{tabular}

Table 1: Size ( 1 ) and density $(\rho)$ for each type of precipitate within both alloys in PA condition ( $t_{a}=3 h$ ).

From images of the kind shown in Fig.2, characteristic features of the different precipitates identified in the PA microstructure were measured. The results are presented in Table 1 . The density $(\rho)$ of plate-shaped precipitates was only slightly lower in Alloy I. Instead, the density of needles in Alloy I, that is close to some of those 
reported for similar precipitates in ref. [8], is four times larger than that of the plateshaped precipitates.

Fig.3 shows an EDS spectrum obtained on a plate-shaped precipitate in Alloy I compared to that obtained in the nearby matrix. Clearly the precipitate is enriched in

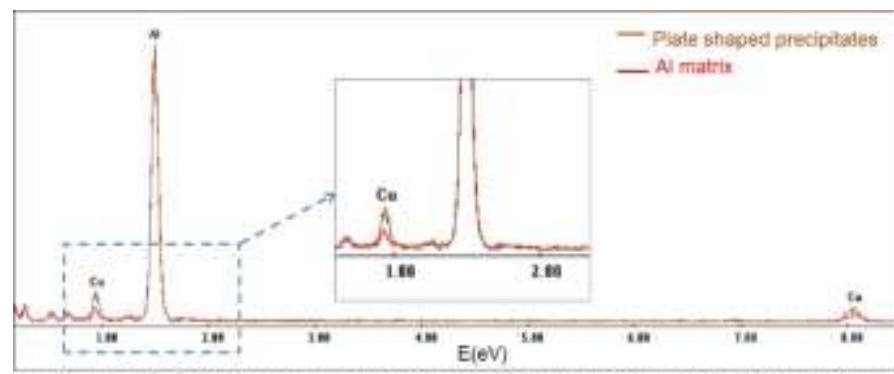

Figure 3: EDS in plate-shaped precipitates and matrix from Alloy I. A higher Cu content is observed in the precipitates.

$\mathrm{Cu}$, but no peaks corresponding to $\mathrm{Mg}$, $\mathrm{Si}$ or $\mathrm{Ge}$ were found. The high $\mathrm{Cu}$ content observed in the matrix is an artifact due to redeposition of $\mathrm{Cu}$ on the specimen surface during the thinning procedure by electropolishing. Since the beam diameter used was slightly lower than $10 \mathrm{~nm}$, the possibility that the plate-shaped precipitates contain a minor amount of $\mathrm{Mg}$, Si and Ge cannot be dismissed.

Figure 4 displays high resolution images of overaged Al-Cu-Mg-Si-Ge $\left(t_{a}=100 \mathrm{~h}\right)$ acquired with the electron beam parallel to the $[001]_{\mathrm{Al}}$ zone axis. Figures $4 \mathrm{a}, \mathrm{b}$ present evidence of heterogeneous nucleation of $\theta^{\prime}$-like plates on the needle-shaped precipitates. HRTEM images of many needle-shaped precipitates were analyzed to identify which phase they belong to. Figures 4c-e present the cross-section of a needleshaped precipitate, its corresponding FFT and a simulated DP. In figure 4c, the cross section is elongated parallel to the $[150]_{A l}$ direction, that has been reported for $Q^{\prime}$ phase precipitates formed in Al-Mg-Si-(Cu) [8]. This is confirmed by observing the good 
match between the FFT shown in Fig $4 d$ with a simulated DP of $Q^{\prime}$ phase in $Z A=[001]_{Q^{\prime}}$ condition (Fig 4e).

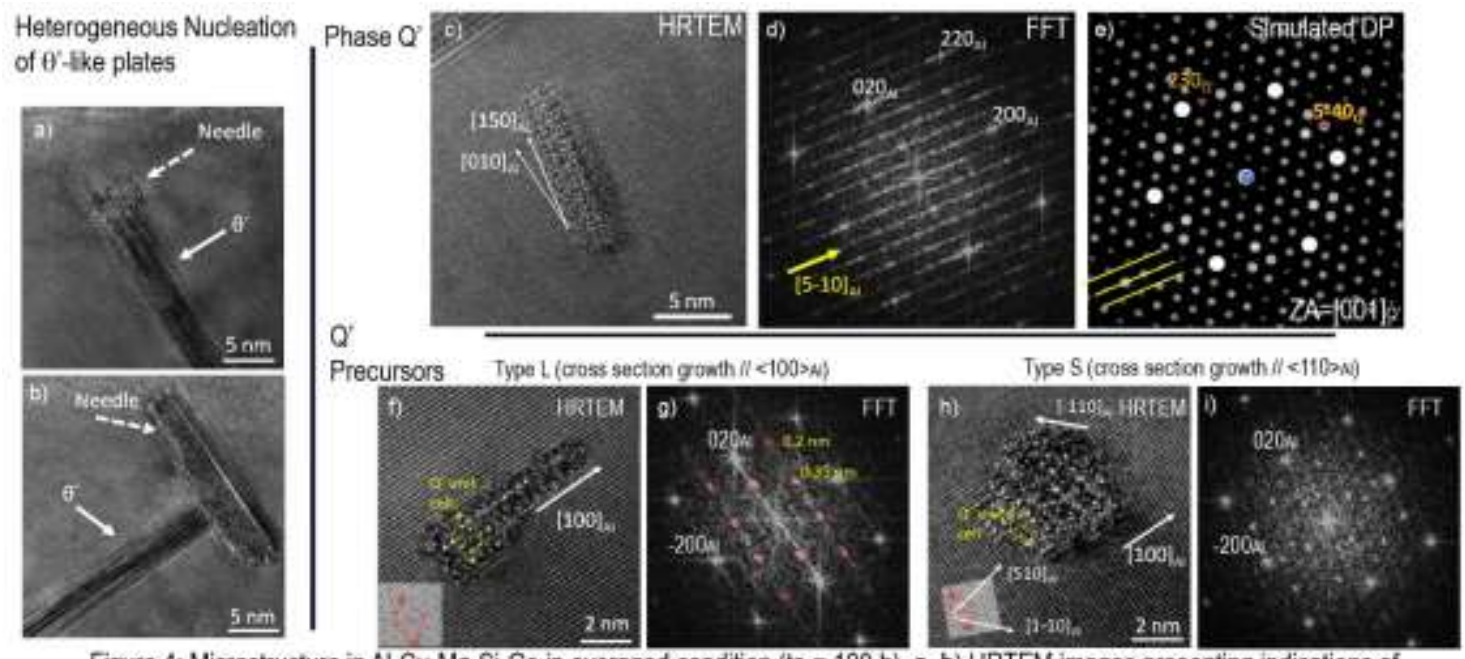

Figure 4: Microstructure in Al-CU-Mg-Si-Ge in overaged condition $(\mathrm{ta}=100 \mathrm{~h})$, a, b) HRTEM images presenting indications of heterogeneous nucleation of the plate-shaped $\theta^{\prime}$-like precipitates over the smaller needle/lath shaped precipitates. c) Cross section of a lath-shaped precipitate oriented parallel to [001] $\mathrm{A}$, d) FFT from c. e) Simulated DP of $\alpha$ phase in [001] $\alpha$ ZA condition shows a good match with the FFT in d. f, h) Cross sections of other needlellath-shaped precipitates oriented parallel to [001]/ and their respective FFTs ( $g$, i) suggesting they are $Q$ ' phase precursors.

Figure $4 \mathrm{f}$ and $4 \mathrm{~h}$ present cross-sections of other needle-like precipitates. In Fig $4 \mathrm{f} \mathrm{a}$ growth direction parallel to $[100]_{\mathrm{Al}}$ can be identified, and in Fig $4 \mathrm{~h}$, although the shape of the cross-section is not so well defined, it appears slightly elongated along the $[110]_{\mathrm{Al}}$ direction. These orientations of the cross-section growth directions belong to two different kinds of $Q^{\prime}$ precursors, the so-called L and S precursors, respectively [8]. To confirm they are $Q^{\prime}$ precursors, a Si-[111] sub-lattice (left-bottom corner of $4 f$ and 4h) and a Q' unit cell were superimposed to the HRTEM images. In the case of the Ltype precursor the Si sub-lattice has one unit vector parallel to $[100]_{\mathrm{Al}}$ and in the case of the S-type precursor it is parallel to $[510]_{\mathrm{Al}}$. In addition, in the FFT from the L-type precursor (Fig. 4g), reflections corresponding to $0.35 \mathrm{~nm}$ and $0.2 \mathrm{~nm}$ interplanar spacings in a hexagonal arrangement were identified, indicating that this precipitate is 
structurally related to $Q^{\prime}$ phase. The FFT of the S-type precursor (Fig. 4i) displays great similarity with the simulated DP from $Q^{\prime}$ phase in $Z A=[001]_{Q^{\prime}}$ condition.

The results from Fig. 4 therefore show that the needle-shaped precipitates correspond to the well characterized $Q^{\prime}$ phase, with composition $\mathrm{Al}_{4} \mathrm{Cu}_{2} \mathrm{Mg}_{8} \mathrm{Si}_{7}$, hexagonal P-6 structure and lattice parameters $a=b=1.0393 \mathrm{~nm}, c=0.40173 \mathrm{~nm}$, or its precursors, reported in Al-Mg-Si-Cu with low Cu:Mg ratio (<0.25, at.\%) [8]. It is assumed that the needle shaped precipitates observed in the PA condition are similar Q' precursors.

\section{Discussion}

Comparison of the microstructures of Alloy I and II shows that introducing Mg into an Al-Cu-Si-Ge alloy does not alter the main precipitation process that involves the formation of plate-shaped precipitates, but inhibits the formation of Si-Ge rod-shaped precipitates, replacing them by a higher density of needle-shaped particles. While in Alloy II the plate-shaped precipitates from $\theta^{\prime}$ phase are responsible for the elevated hardness [4,11], in Alloy I not only the plate shaped precipitates harden the alloy but also the fine dispersion of needle-shaped precipitates, as reported in $\mathrm{Al}-\mathrm{Cu}-\mathrm{Mg}$ with trace additions of Ge [12]. In the present work, the fine dispersion of precipitates were identified as precursors of the Q' phase. These precipitates contribute to increase peak hardness in two ways: by stimulating the formation of plate-shaped precipitates through heterogeneous nucleation and by their own hardening effect. The Q' phase has been observed in alloys with no Ge content, suggesting that this element is not essential to form such precipitates, and could be replaced by Si. Interestingly, comparing the different precipitate densities in Alloy I and assuming that all the plate-shaped precipitates in Alloy I are formed by heterogeneous nucleation, 
only about one quarter of the needle-shaped precipitates serve as nucleation sites for the plate-shaped precipitates. Instead, in Alloy II, the density of rod-shaped Si-Ge precipitates is very similar to that of plate-shaped $\theta^{\prime}$ precipitates, indicating that all the Si-Ge particles are nucleation sites for the $\theta^{\prime}$ phase. In Alloy I, different kinds of needleshaped precipitates with different coherence relationships with the matrix are formed, suggesting that not all of them are efficient sites for heterogeneous precipitation of the plate-shaped particles. Therefore, by increasing the fraction of needle-shaped precipitates that favor heterogeneous nucleation, an even higher density of plateshaped precipitates might be formed and thus even higher peak hardness values may still be achieved.

The present results can also be analyzed as the effect of minor additions of $\mathrm{Si}$ and $\mathrm{Ge}$ on $\mathrm{Al}-\mathrm{Cu}-\mathrm{Mg}$, where the main precipitation process is the formation of lath-shaped Sphase precipitates $[6,20]$. No S-phase precipitates were observed in the microstructure of Alloy I, indicating that the addition of Si and Ge inhibits the formation of this phase, favoring instead the formation of plate-shaped precipitates similar to the $\theta^{\prime}$ phase.

\section{Conclusions}

To summarize, hardness measurements at $190^{\circ} \mathrm{C}$ showed that the addition of $\mathrm{Mg}$ to the Al-Cu-Si-Ge alloy resulted in significantly higher hardness already at the initial stages of aging and particularly at PA. The time to PA was preserved and the enhanced hardness prevailed even for prolonged ageing times, indicating a high overaging resistance due to a stable precipitate distribution.

The PA microstructure in both alloys was dominated by plate-shaped precipitates parallel to the $\{100\}$ matrix planes. In Alloy II these precipitates correspond to the $\theta^{\prime}$ 
phase and in Alloy I they showed analogous characteristics, indicating a very similar phase. In Alloy I a high density of needle-shaped precursors of the Q' phase was found, only a fraction of which served as nucleation sites for the plate-shaped precipitates. The increased hardness compared to Alloy II (without $\mathrm{Mg}$ ) is therefore attributed to the contribution of both plate-shaped and needle-shaped precipitates.

\section{Acknowledgments}

This work was partially supported by the ANPCYT through grant PICT 2011-0643 and PICT 2015-1641 and by UN Cuyo through grant 06/C523. The participation of N.M. was possible through the support of CNEA and Instituto Balseiro for the summer scholarships programme. The authors also want to acknowledge the Metal Physics Department at HZG for the use of the microscopy facilities.

\section{Declaration of interests: None}

\section{References}

[1] I. J. Polmear, Light Alloys, fourth ed., Elsevier, Oxford, 2006.

[2] L. F. Mondolfo, Aluminium Alloys, first ed., Butterworths \& Co Ltd, London, 1976.

[3] D. A. Porter, K. E. Easterling, Phase transformations in metals and alloys, second ed., Chapman-Hall, London, 1992 .

[4] D. Mitlin, V. Radmilovic, U. Dahmen, J. W. Morris Jr, Precipitation and Ageing in AlCuSiGe, Metall Mater Trans A 32 (2001) 197-199.

[5] J.M. Silcock, T.J. Heal, H.K. Hardy, The structural ageing characteristics of ternary Aluminum-Copper alloys with Cadmium, Indium or Tin, J Inst Met 84 (1955) 23-31.

[6] M. Murayama, K. Hono, M. Saga, M. Kikuchi, Atom probe studies on the early stages of precipitation in Al-Mg-Si alloys, Mater Sci Eng A 250 (1998) 127-132. 
[7] G. A. Edwards, K. Stiller, G. L. Dunlop, M. J. Couper, The precipitation sequence in Al-Mg-Si alloys, Acta Mater 46, 11 (1998) 3893-3904.

[8] C.D. Marioara, S.J. Andersen, T. N. Stene, H. Hastings, J. Walmsley, A.T.J. Van Helvoort, R. Holmestad, The effect of Cu on precipitation in Al-Mg-Si alloys, Philos Mag 87 (2007) 3385-3413.

[9] R. Bjørge, P.N.H. Nakashima, C.D. Marioara, S.J. Andersen, B.C. Muddle, J. Etheridge, R. Holmestad, Precipitates in an Al-Mg-Ge alloy studied by aberration-corrected scanning transmission electron microscopy, Acta Mater 59 (2011) 6103-6109.

[10] R. Bjørge, S.J. Andersen, C.D. Marioara, J. Etheridge, R. Holmestad, Scanning transmission electron microscopy investigation of an Al-Mg-Si-Ge-Cu alloy, Philos. Mag. 92 (2012) 3983-3993.

[11] S. P. Ringer, K. Hono, Microstructural evolution and age hardening in aluminium alloys: atom probe field-ion microscopy and transmission electron microscopy studies, Materials Characterization 44 (2000) 101-131.

[12] S.P Ringer, G.C. Quan, T. Sakurai, Solute clustering, segregation and microstructure in high strength low alloy Al-Cu-Mg alloys, Mater Sci Eng A 250 (1998) 120-126.)

[13] S.P. Ringer, S.P. Swenser, B.C. Muddle, I.J. Polmear, T. Sakurai, APFIM/TEM Observations of a High Strength-Creep Resistant Al-Cu-Mg-Si-Ge Alloy, Mater Sci Forum, 217-222, (1996) 689-694.

[14] S.P. Ringer, K.S. Prasad, G.C. Quan, Internal co-precipitation in aged Al-1.7Cu-0.3Mg-0.1Ge (at.\%) alloy, Acta Mater 56 (2008) 1933-1941.)

[15] M.V. Castro Riglos, A. Tolley, N. Morello, E. Muzaber, Mechanical and Microstructural Characterization in Al-Cu-Mg Based Alloys, Proceedings of SAM-CONAMET (2013) Misiones, Argentina. T5C-14.

[16] M.V. Castro Riglos, M. Taquire de la Cruz, A. Tolley, Accelerated age hardening by plastic deformation in Al-Cu with minor additions of Si and Ge, Scripta Mater 64 (2011) 169-172. [17] R.F. Egerton, Electron Energy Loss Spectroscopy in the Electron Microscope, second ed., Plenum Press, New York, 1996.

[18] jems: www.jems-saas.ch/Home/jemsv4 6228u2018.htm

[19] Gatan Microscopy Suite Software: www.gatan.com/products/tem-analysis/gatan-microscopy-suitesoftware 
[20] S. P. Ringer, K. Hono, I. J. Polmear, T. Sakurai, Nucleation of precipitates in aged Al-Cu-Mg-(Ag) alloys with high Cu:Mg ratios, Acta Mater 44 (1996) 1893-1898.

Graphical Abstract

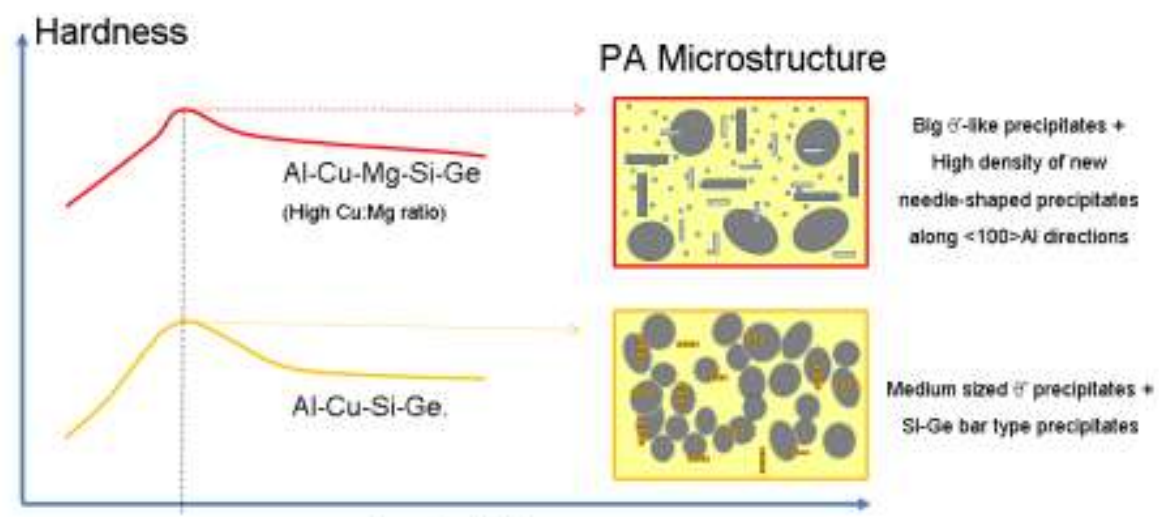

Ageing Time

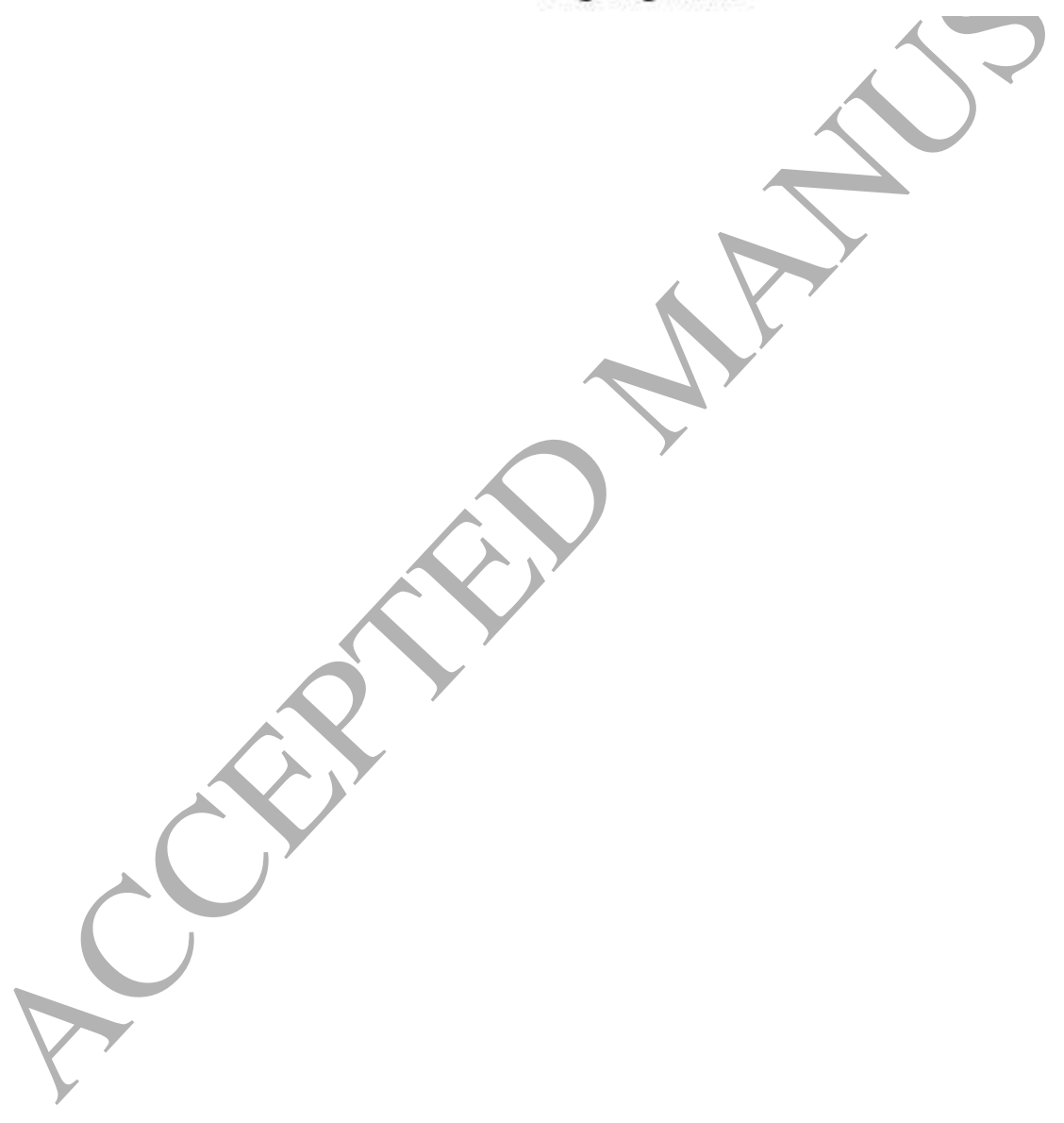

